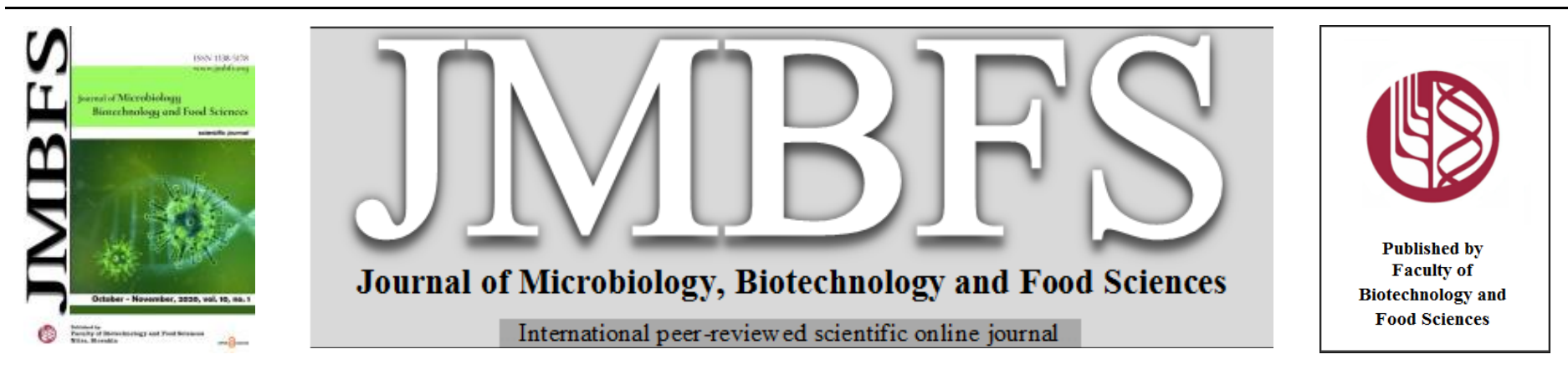

\title{
PRODUCTION OF SYNBIOTIC PRODUCT CONTAINING GALACTO-OLIGOSACCHARIDES AND SACCHAROMYCES BOULARDII AND EVALUATION OF ITS IN-VITRO BIFIDOGENIC EFFECT
}

\author{
Farah Javed $^{1}$, Zeshan Ali ${ }^{2}$, Sanaullah Iqbal*1, Naveed Ahmed ${ }^{3}$, Zubair Farooq ${ }^{1}$, Faiza Masood and Muhammad Nawaz $^{4}$
}

\section{Address(es):}

${ }^{1}$ Department of Food Science and Human Nutrition, University of Veterinary and Animal Sciences, Lahore, Pakistan.

${ }^{2}$ College of Food Engineering and Nutritional Sciences, Shaanxi Normal University. Xi'an 710119, China.

${ }^{3}$ Department of Microbiology, Pakistan Kidney and Liver Institute and Research Center (PKLI \& RC), Lahore, Pakistan.

${ }^{4}$ Department of Microbiology, University of Veterinary and Animal Sciences, Lahore, Pakistan.

*Corresponding author: sanaullah.iqbal@uvas.edu.pk

doi: 10.15414/jmbfs.2020.10.2.197-200

\section{ARTICLE INFO}

Received 22. 12. 2019

Revised 2. 6. 2020

Accepted 11. 6. 2020

Published 1. 10. 2020

$\underline{\text { Regular article }}$

open ${ }_{\text {ACCESS }}$

\begin{abstract}
The galacto-oligosaccharides and Saccharomyces boulardii are very useful for the intestinal microbiota. The yeast acts as probiotic and used for the reduction of monosaccharides from GOS mixture. The present study was concerned with the production of synbiotic product from GOS and $S$. boulardii through transgalactosylation process. The GOS was produced from $\beta$-galactosidase (156 U/1 ml of lactose solution) of Kluyveromyces lactis using lactose $(250 \mathrm{~g} / \mathrm{L})$ as substrate at $37^{\circ} \mathrm{C}$. The GOS mixture was analyzed through thin layer chromatography and megazyme kit. The maximum production of GOS occurs after $5 \mathrm{hr}$ at $37^{\circ} \mathrm{C}$ with phosphate buffer $(\mathrm{pH} 6.5)$. The GOS mixture was treated with probiotic $S$. boulardii. The monosaccharides were reduced at $37^{\circ} \mathrm{C}$ after $4 \mathrm{hrs}$ using $300 \mu 1$ yeast $/ 5 \mathrm{ml}$ GOS mixture. Then synbiotic product was formed and undergoes lyophilization procedure. The total yeast count was $3.9 \times 10^{4} \mathrm{CFU} / \mathrm{g}$ in lyophilized product. The in vitro bifidogenic effect was determined. Bifidobacterium shows more positive effect towards prebiotic and combined effect of prebiotic and probiotic as compared to Lactobacillus.
\end{abstract}

Keywords: GOS, Saccharomyces boulardii, Transgalatosylation, Synbiotic product

\section{INTRODUCTION}

The synergistic combination of prebiotic and probiotic is known as synbiotic. The prebiotic favors the probiotic and activates the host's beneficial intestinal microflora (Underwood et al., 2009). The combination of oligofructose and bifidobacteria is the example of symbiotic (Schaafsma, 2008).

Prebiotics are classified as those ingredients that are fermented and permit changes in composition and activity in the intestinal microbes that are beneficial to host. The examples are fructooligosaccharides (FOS), galactooligosaccharides (GOS), and inulin. The health benefits of prebiotic are prevention of diarrhoea or obstipation, modulation of the metabolism of the intestinal flora and cancer prevention. GOS are carbohydrates that are non-digestible and fermented by colon bacteria. They have great role in functional foods due to their benefits such as mineral absorption, role in lipid breakdown and anti-inflammatory (Schaafsma, 2008), show less potential to dental caries.

GOS can be produced using lactose through transgalactosylation process with the help of $\beta$-galactosidase enzyme. The transgalactosylation is a process in which transgalacto-oligosaccharides (TOS) are produced by enzyme using lactose as substrate. The mono and disaccharides are also produced that are not required in prebiotic production. They are undesirable because they increase the caloric value of product by absorbing in small intestine. The hydrolysis of glycosidic bonds is done by $\beta$-galactosidase enzyme. Therefore, purity of GOS is necessary from these byproducts. It helps to evaluate the functional properties of GOS such as in vitro prebiotic activity and determination of structures (Hernandez et al., 2009). The GOS with less monosaccharides can be produced through several methods which include size exclusion chromatography, activated charcoal treatment, diafilteration and yeast treatments. Hernandez et al. (2009) purified GOS using $S$. cerevisiae and removed all monosaccharides from mixture (Hernandez et al., 2009). Gaulas et al. (2007) examined the reduction of galactose with $S$. cerevisiae (Goulas et al., 2007). Kunova et al. (2011) removed mono as well as disaccharides from GOS mixture through Lactobacillus helveticus (Kunova et al., 2012). The chromatographic purification was done by (Rodriguez Colinas et al., 2013).

The term probiotic is defined as microorganisms that are beneficial to host when sufficient amount of which enters into small intestine. The examples of probiotics used in food are Lactobacillus reuteri, L. casei and L. acidophilus. Saccharomyces bulardii is well known yeast which often used as probiotic and dietary supplement. It reduces the diarrhea, alleviates inflammatory diseases related to intestine, helpful in prevention of infection of Helicobacter pylori, inhibits the growth of pathogens (Geyik et al., 2006) and stimulates antibody production against diarrhea causing toxin (Qamar et al., 2001).

In Pakistan there is no pharmaceutical and food industry which produces synbiotic such as combination of (GOS) and S. bulardii. Mostly GOS are imported from Yakult central institute for microbiological research, Kunitachi, Tokyo, Japan and Nissin sugar manufacturing Co Ltd. There is a need to produce synbiotic at commercial level in Pakistan due to its beneficial effects and increasing demands.

\section{MATERIALS AND METHODS}

All chemicals required in this research were of highest possible purity and were procured from (Merck, Germany) unless otherwise stated. The $\beta$-galactosidase from Kluveromyces lactis enzyme was purchased from Sigma Aldrich, UK Thymol (applichem, Germany), and Lactobacillus selective agar from (LAB, Germany).

\section{Transgalactosylation}

The transgalactosylation process was done with lactose $(250 \mathrm{~g} / \mathrm{L}$ of phosphate buffer). Different $\mathrm{pH}(5-7)$, enzyme concentration (156U/1 ml of lactose solution) and time of incubation $(0-5 \mathrm{~h})$ were optimized. The process was carried out at $37^{\circ} \mathrm{C}$.

\section{Analysis of GOS}

GOS was analyzed by thin layer chromatography (TLC). The glucose (GOPOD Assay), galactose and lactose were measured using megazyme assay kits (Wicklow, Ireland) following standard procedure given in manual. The GOS mixture was analyzed through TLC using following method. The standards samples and samples obtained after transgalactosylation process $(2 \mu \mathrm{l})$ were applied on silica gel plate. The running buffer (n-butanol, n-propanol, ethanol, and distilled water) was used in ratio of $2: 3: 3: 2$, respectively. The staining buffer ( $0.6 \%$ thymol, $95 \mathrm{ml}$ ethanol and $5 \mathrm{ml} \mathrm{H}_{2} \mathrm{SO}_{4}$ ) was sprayed on dried plate. The sugar stains were visible after $110^{\circ} \mathrm{C}$ heating in hot air oven. 


\section{Saccharomyces boulardi}

Biflor sachet (Bocodex) (250mg) was added in 50ml sabouraud dextrose broth aseptically and incubated at $37^{\circ} \mathrm{C}$ on shaking incubator for 3 days.

\section{Removal of monosaccharides from GOS through $S$. boulardii}

Different probiotic concentrations $(100 \mu 1-400 \mu 1)$ were examined for the maximum removal of monosaccharides from GOS mixture. The effect of different time of incubation $(0-48 \mathrm{hr})$ was evaluated for removal of monosaccharides. After optimization the following procedure was performed. $S$ boulardii $(300 \mu \mathrm{l})$ was added in $5 \mathrm{ml}$ of GOS solution. The reaction was carried on $37^{\circ} \mathrm{C}$ for $4 \mathrm{hr}$. The samlpe was heated at $90^{\circ} \mathrm{C}$ for $5 \mathrm{~min}$ and centrifuged at 10000 $\mathrm{rpm}$ for $5 \mathrm{~min}$. The supernatants were separated in eppendorfs. The analysis was done through thin layer chramotgraphy (TLC) and megazyme kit. After optimization conditions of transgalactosylation and monosaccharides removal, the synbiotic product was prepared. At the time of maximum amount of GOS, the product was freezed at $-20^{\circ} \mathrm{C}$ followed by lyophilization.

\section{Lyophilization}

The product was frozen. After freezing, the product was placed under vacuum.Heat was applied to frozen product. Low temperature condenser plates were allowed to convert it into solid (Sharma et al., 2019).

\section{Total count of $S$. boulardii}

The synbiotic $(1 \mathrm{ml})$ was taken in $9 \mathrm{ml}$ normal saline solution. Tenfold serial dilutions were made in different seven test tubes. The sample $(100 \mu 1)$ from each test tube was separated on sabouraud dextrose agar (SDA) and was incubated at $37^{\circ} \mathrm{C}$ for 3 days. The plate containing 30-300 colonies was considered for colony forming unit (CFU). The CFU/g was calculated as follows;

$\mathrm{CFU} / \mathrm{g}=\quad$ No of colonies $\times$ dilution factor $\times$ 10

\section{In vitro bifidogenic effect of GOS}

Bifidogenic effect of GOS was checked in vitro by comparing with other sugars. The assays were done for each sugar and $10 \% \mathrm{w} / \mathrm{v}$ of the particular sugar was added aseptically. MRS broth was taken in five (labeled as 1, 2, 3, 4 and 5) sterilized test tubes containing $4 \mathrm{ml}$ broth in each. In test tube 1 no sugar was added. It was treated as control. In test tube 2 , GOS $(10 \% \mathrm{w} / \mathrm{v})$ was added. In test tube 3, 4 and 5 glucoses $(10 \%$ w/v), lactose $(10 \%$ w/v) and GOS treated with $S$ boulardii $(10 \% \mathrm{w} / \mathrm{v})$ respectively.

Fecal sample of infant was used as a source of bifidogenic bacteria. For the isolation of bifidobacterium species, fresh infants stool specimens were suspended in sterile saline $(9 \mathrm{~g}$ of $\mathrm{NaCl}$ per liter), followed by tenfold dilutions in the same suspension medium. Sample $(100 \mu \mathrm{l})$ of each dilution (e.g. $10^{-1}$ to $\left.10^{-7}\right)$ was pipetted onto MRS Agar $+0.05 \%$ cystiene (bifidus selective agar) and MRS Agar (lactobacillus selective Agar), which was then spread, inoculated and incubated anaerobically in anaerobic jar having anaerobe sachet at $37^{\circ} \mathrm{C}$. A loop full of the isolated bifidobacterium and lactobacillus cultures were inoculated in MRS broth in different test tubes with different sugars as illustrated in above mentioned table. Cultivation was monitored at $37^{\circ} \mathrm{C}$ for $48 \mathrm{hr}$ anaerobically (Rossi et al., 2005). Growth of bacteria was checked by measuring optical density at $\mathrm{OD}_{600}$

\section{Statistical Design}

The comparison between GOS and treated GOS with yeast will be done using Ttest. The data regarding growth of bifidobacteria and lactobacilli will be analyzed by one-way ANOVA using SPSS version 18.0. $P$ values $\leq 0.05$ will be considered significant.

\section{RESULTS}

\section{Optimization conditions of transgalactosylation reaction}

The effect of different $\mathrm{pH}$ of phosphate buffer on transgalactosylation process was recorded. The $\mathrm{pH}$ was adjusted from 5 to 7 . The highest conversion of lactose occurs at $\mathrm{pH} 6.5$ of phosphate buffer. At $\mathrm{pH}$ lower or higher than 6.5 , there is no or very mild transgalactosylation occur. The various concentrations of enzyme were evaluated to check the optimal enzyme concentration at which maximum transgalactosylation process occur. The enzyme concentrations were $10 \mu \mathrm{l}-200 \mu \mathrm{l}$. At equal concentration of lactose solution and enzyme concentration $(1: 1)$, there is no production of galactooligosaccharides (GOS). The maximum GOS was produced with $30 \mu 1$ enzyme. As enzyme concentration increases $(50 \mu 1$ $200 \mu 1$ ), the transgalactosylation process decreases. Hence, $30 \mu \mathrm{l}$ enzyme concentration was considered optimal for further whole experiments. Different time of incubation (15 min-5h) was examined to obtain optimal time for the higher production of GOS. After $4 \mathrm{hr}$ maximum GOS was produced. At 2 or $3 \mathrm{hr}$ very less quantity of GOS was produced. Therefore, $4 \mathrm{hr}$ was considered optimal for further experiments.

\section{Production of galacto-oligosaccharides}

Lactose $(250 \mathrm{~g} / \mathrm{L})$ was used for the production of GOS. The high concentration of lactose facilitates the reaction of transgalactosylation. Lactose solution $(10 \mathrm{ml})$ was used to optimize the all conditions. After optimization, the GOS was prepared using $500 \mathrm{ml}$ lactose $(250 \mathrm{~g} / \mathrm{L})$, lactose was dissolved in $50 \mathrm{mM}$ sodium dihydrogen phosphate buffer $(\mathrm{pH} 6.5)$, and $1500 \mu 1$ enzyme. The reaction was carried on at $37^{\circ} \mathrm{C}$ for $4 \mathrm{hr}$ at $150 \mathrm{rpm}$. Initially, the glucose and galactose were formed as the reaction proceeded. As the reaction catalyzed further by enzyme, the GOS were prepared. After the fourth hour the maximum GOS were produced, approximately $40 \%$ of total sugars present in the mixture. As the time was increased the concentration of GOS was decreased because these are not thermodynamically stable products. These are formed for very short interval of time.

\section{Analysis of GOS}

\section{Thin layer chromatography}

Thin layer chromatography (TLC) was used various time to check the composition of GOS mixture produced at the end of transgalactosylation procedure. TLC was performed using lactose at different interval of time and with different concentration of enzyme to optimize the conditions where maximum GOS was produced. Figure 1 shows the TLC $(10 \mathrm{ml}$ lactose solution and $30 \mu 1$ enzyme concentrations).

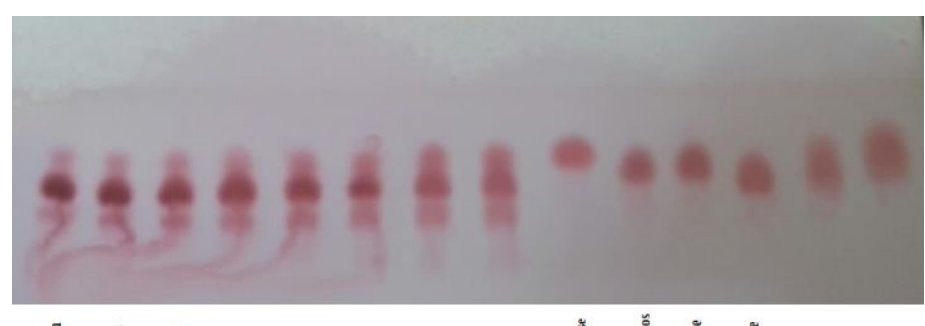

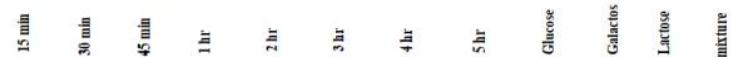

Figure 1 Thin layer chromatography (TLC) at $37^{\circ} \mathrm{C}$ at different interval of time $(15 \mathrm{~min}-5 \mathrm{hr})$ with $30 \mu \mathrm{l}$ enzyme per $10 \mathrm{ml}$ of lactose solution $(\mathrm{pH} 6.5)$. Production of GOS is compared with standard solutions $(20 \mathrm{~g} / 1$ glucose, $20 \mathrm{~g} / 1$ galactose, $20 \mathrm{~g} / 1$ lactose and $20 \mathrm{~g} / \mathrm{l}$ mixture of glucose, galactose and lactose

\section{Quantification of GOS through megazyme kit}

The maximum GOS production was at $\sim 75 \%$ lactose conversion after $4 \mathrm{hr}$ of reaction. The final mixture contained $30 \% \mathrm{GOS}, 30 \%$ D-glucose, $15 \%$ D galactose and $25 \%$ untransgalactosylated lactose.

\section{Saccharomyces boulardii}

Saccharomyces boulardii was produced using biflor sachet $(250 \mathrm{mg})$ grown in $50 \mathrm{ml}$ sabouraud dextrose broth aseptically at $37^{\circ} \mathrm{C}$ on shaking incubator for 3 days. The simple and negative staining was performed for the identification of the yeast. The various concentrations of probiotic ( $S$. boulardii) were examined to check the optimal reduction of monosaccharides from GOS mixture. The probiotic concentrations were $100 \mu 1-400 \mu 1$. The maximum reduction was occurred with $300 \mu \mathrm{l}$ probiotic in $5 \mathrm{ml}$ prebiotic solution (GOS mixture) Therefore, $300 \mu \mathrm{l}$ culture of yeast was used for further experiments. Different time of incubation $(15 \mathrm{~min}-5 \mathrm{~h})$ was evaluated to obtain optimal time for the highest reduction of monosaccharides from GOS mixture. After $4 \mathrm{hr}$ maximum reduction was occurred. At 2 or 3 hr very less quantity of glucose was reduced Therefore, $4 \mathrm{hr}$ was considered optimum.

\section{Removal of monosaccharides from GOS through S. boulardii}

S. boulardii $(300 \mu 1)$ was used for the removal of monosaccharides especially glucose. The conditions were optimized using $5 \mathrm{ml}$ of GOS mixture. The reaction was carried on $37^{\circ} \mathrm{C}$ for $4 \mathrm{hr}$. At the beginning of reaction, no glucose was removed. But with the passage of time, the glucose was reduced. The maximum reduction was occurred after $4 \mathrm{hr}$. The samlpe was heated at $90^{\circ} \mathrm{C}$ for $5 \mathrm{~min}$ and centrifuged at $10000 \mathrm{rpm}$ for $5 \mathrm{~min}$. The supernatants were separated in eppendorfs. The analysis was done through thin layer chramotgraphy (TLC) shown in. The synbiotic product containing GOS and S. boulardii was prepared. The product was lyophilized under the following conditions. 


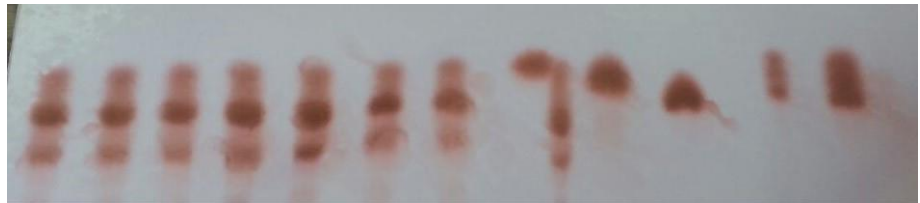

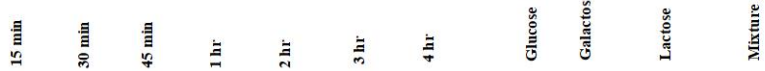

Figure 2 Thin layer chromatography (TLC) for the reduction of monosaccharides with time (15 min to $4 \mathrm{hr}$ ). Reduction of monosaccharidesis compared with standard solutions (20g/l glucose, $20 \mathrm{~g} / \mathrm{l}$ galactose, $20 \mathrm{~g} / \mathrm{l}$ lactose and $20 \mathrm{~g} / \mathrm{l}$ mixture of glucose, galactose and lactose

\section{Colony forming unit of $S$. boulardii in lyophilized product}

The colony count of yeast in lyophilized synbiotic product was identified using 10 -fold dilution procedure. The plate containing 39 colonies was selected because it was within the standard range i.e.; 30-300 colonies. The CFU/g was calculated using following formula

$\mathrm{CFU} / \mathrm{g}=$ No of colonies $\times$ dilution factor $\times 10$

$\mathrm{CFU} / \mathrm{g}=39 \times 10^{2} \times 10$

$\mathrm{CFU} / \mathrm{g}=3.9 \times 10^{4}$

\section{In vitro bifidogenic effect}

The in vitro bifidogenic effect was studied for maximum production. Different sugars glucose, lactose, GOS, GOS treated with $S$. boulardiiwere examined after inoculation of Lactobacillus and Bifidobacterium. The values of control were 0.337 in case of Lactobacillus and 0.357 in case of Bifidobacterium. The higher results in terms Lactobacillus growth $(\mathrm{p} \leq 0.05)$ was with glucose $(0.567)$. The value of GOS treated with yeast $(0.508)$ was closer to the value of glucose. It showed that the synbotic product has good effect. The best results in terms Bifidobacterium growth was with GOS (0.433). In this case the value of glucose $(0.402)$ was less than that of both GOS and GOS treated with yeast $(0.432)$. It means that Bifidobacterium shows more positive effect towards prebiotic and combined effect of prebiotic and probiotic as compared to Lactobacillus.

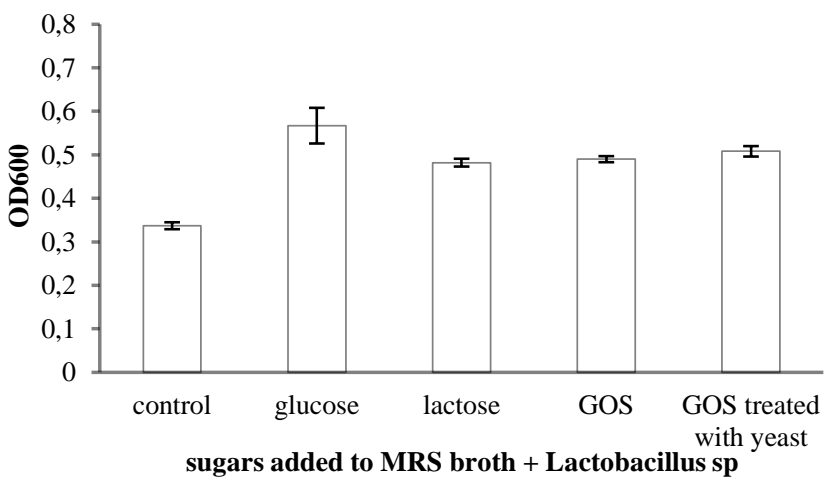

Figure 3 Behavior of Lactobacillus sp. with different sugars in MRS broth. The standard error bars indicate standard deviation $( \pm \mathrm{sd})$ among the three parallel replicates. The values differ significantly at a level ofp $\leq 0.05$

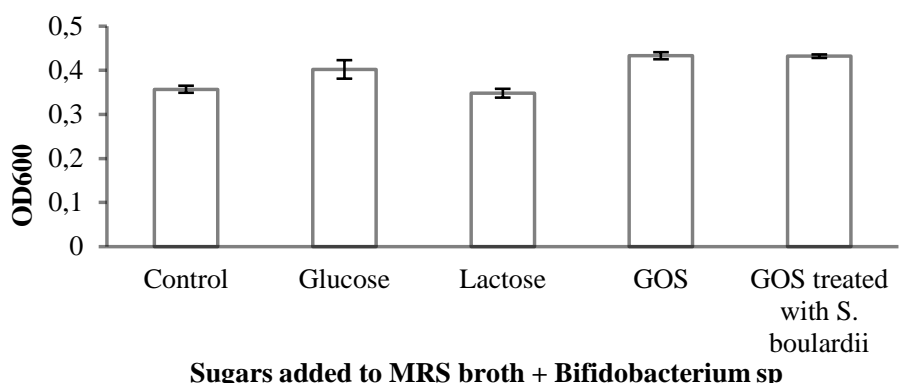

Figure 4 Behavior of Bifidobacterium sp. with different sugars in MRS broth The standard error bars indicate standard deviation $( \pm \mathrm{sd})$ among the three parallel replicates. The values differ significantly at a level of $\mathrm{p} \leq 0.05$

\section{DISCUSSION}

The mixture of prebiotics and probiotics is known as Synbiotic product. The prebiotics enhance the growth of probiotic bacteria in the synbiotic product and also helpful for host's microflora (Underwood et al., 2009). The present study is done to check either the combination containing galactooligosaccharde (GOS) and $S$. boulardii is more effective than the separate effect of prebiotics and probiotics. There is no review on the synbiotic at the clinical side as in formula fed term infants. Only the impact of prebiotics and probiotics has been examined in term of infants to prevent diseases (Osborn and Sinn, 2007).

The pronounced role of prebiotics has been determined through advanced research based on in vitro and in vivo studies. Now a day there is much awareness of prebiotics in nutritional and medical aspects. Prebiotics was first defined as non-digestible and fermented ingredients that allow specific changes in composition and activity in the intestinal microflora that give benefits to host health (Sanders et al., 2019). GOS are transparent in nature, high soluble in water and more viscous than high fructose syrups. The sweetness of GOS is third time less than sucrose and has low potential to cause dental cares as determined in in vitro studies (Kirsten et al., 2019). GOS can be added in several foods due to its stability, good taste, ability to enhance texture and mouth feels of foods. Therefore, GOS and other prebiotics such as FOS are widely used for commercial purposes in infant formulas, dairy products, sauces, soups, breakfast cereals, beverages, snack bars, ice creams, animal feeds, and as sugar replacements (Macfarlane et al., 2008).

The physiochemical and physiological properties of GOS mainly depend on the degree of polymerization and end products of transgalactosylation. The linkages formed in final products depend on the source of enzyme and conditions during the reaction. The galactosyl acceptor and active site of catalyst play a major role in formation of GOS mixture. $\beta$-galactosidase from microbial sources produces different linkages such as $\beta-(1 \rightarrow 3), \beta-(1 \rightarrow 4), \beta-(1 \rightarrow 6)$ and combination of these linkages. The $\beta$-galactosidase derived from Bacillus circulans and Cryptococcus laurentii has $\beta$ - $(1 \rightarrow 4)$ linkage between two galactose units. While the $\beta$ galactosidase of Aspergillus oryazae and Streptococcus thermophilus produces product having $\beta-(1 \rightarrow 6)$ linkages (Tzortzis and Vulevic, 2009). In present research work $\beta$-galactosidase from Kluyveromyces lactis is used that containing $\beta-(1 \rightarrow 4)$ linkage (Kaplan and Hutkins, 2000). Due to these linkages GOS are resistant to adverse conditions of temperature and acidity. They remain stable at high temperature in acidic conditions even at $160^{\circ} \mathrm{C}$ for $10 \mathrm{~min}$ at $\mathrm{pH} 7$. GOS are also stable at room temperature in acidic environment even for long time. Due to this property GOS can be used in beverages that stored at room temperature for several months (Leroy and De Vuyst, 2004). They are used as low caloric sweeteners in fermented milk products, bread and beverages. The products of transgalactosylation containing $\beta-(1 \rightarrow 6)$ linkage showed selectivity towards Bifidobacteria (Kaplan and Hutkins, 2000).

The production of GOS through $\beta$-galactosidaseenzyme using lactose as substrate has been studied over the last 50 years because of its several functions as prebiotics (Yazdi et al., 2019). In present studies $\beta$-galactosidase was procured from Sigma, Aldrich. $10 \mathrm{ml}$ of lactose solution $(250 \mathrm{~g} / \mathrm{L})$ was taken and transgalactosylation process was performed to optimize the conditions. The sampling was done at different interval of time and subjected to heat for $5 \mathrm{~min}$ at $90^{\circ} \mathrm{C}$ to denature the enzyme. After that samples were analyzed through thin layer chromatography (TLC) and megazyme kit.

The results in fig 1 show that transgalactosylation was occurred maximum after $4^{\text {th }}$ hours of reaction. The lactose is converted in to various products. The conversion of lactose can be easily seen in fig when compared to standards i.e.; glucose, galactose, lactose and mixture of these three sugars. The lactose was converted into GOS mixture by breaking $\beta$-linkages using $30 \mu 1$ enzyme/10ml lactose solution at $37^{\circ} \mathrm{C}$ for $4 \mathrm{hrs}$.

In another study GOS was produced from $\beta$-galactosidase of Lactobacillusreuteri L103 andLactobacillus plantarum. The process was carried out at $37^{\circ} \mathrm{C}$ using lactose $\left(600 \mathrm{mM}\right.$ in $50 \mathrm{mM}$ sodium phosphate buffer, $\mathrm{pH}$ 6.5). $\mathrm{MgCl}_{2}(1 \mathrm{mM})$ was also added in reaction mixture. The $\beta$-galactosidase activity was determined in term of lactose unit $\left(\mathrm{U}_{\text {lac }}\right)$. The yield of GOS was $41 \% \mathrm{w} / \mathrm{w}$ of total sugars in case of L. plantarum and $36 \% \mathrm{w} / \mathrm{w}$ of total sugars in case of $L$. reuteri $\mathrm{L} 103$. The major components of GOS mixture were characterized using TLC, high performance anion exchange chromatography with pulsed amperometric detection (HPAEC-PAD) and capillary electrophoresis (Splechtna et al., 2007a). The production of GOS from purified recombinant $\beta$-galactosidase of Lactobacillus sakei Lb790 was also examined. The process was carried out at $37^{\circ} \mathrm{C}$ using 1.2 lactase $\mathrm{U}$ per $\mathrm{ml}$ of reaction mixture at $300 \mathrm{rpm}$. The initial concentration of lactose was $215 \mathrm{~g} / \mathrm{L}$. The lactose was dissolved in sodium phosphate buffer $(50 \mathrm{mM}, \mathrm{pH} 6.5)$. After the reaction was completed, the GOS mixture was analyzed through TLC, (HPAEC-PAD) and capillary electrophoresis (CE) (Splechtna et al., 2007b).

The GOS mixture was produced by $\beta$-galactosidase of selected probiotic bacteria (Bifidobacterium bifidum BB-12, Bifidobacterium infantis DSM-20088, Bifidobacterium pseudolongum DSM-20099, Bifidobacteriium adolescentis B-7, Bifidobacterium angulatum). When this mixture was analyzed through TLC, the different spectra were seen which was different from standard i.e. Oligomate 55. 
In present study the GOS mixture was treated with probiotic ( $S$. boulardii). The conditions were optimized using $5 \mathrm{ml}$ of GOS mixture. $S$. boulardii $(300 \mu \mathrm{l})$ was used. The reaction was carried on $37^{\circ} \mathrm{C}$ for $4 \mathrm{hr}$. At the beginning of reaction, no glucose was removed. But with the passage of time, the glucose was reduced The maximum reduction was occurred after $4 \mathrm{hr}$. The samlpe was heated at $90^{\circ} \mathrm{C}$ for $5 \mathrm{~min}$ and centrifuged at $10000 \mathrm{rpm}$ for $5 \mathrm{~min}$. The supernatants were separated in eppendorfs. The analysis was done through thin layer chramotgraphy (TLC).

A study was showed by (Splechtna et al., 2007b) on the removal of glucose and galactose from GOS mixture. The separation was done using the Unibead UBK 530 strongly acidic cation-exchange resin (Mitsubishi Chemical Industries). The sample was subjected to freeze dried and desalted. After that it was dissolved in water. The sugars were approximately $70 \%(\mathrm{w} / \mathrm{v})$ in solution. The $3.5 \mathrm{ml}$ of the solution was added to a column. The reaction was carried out at $70^{\circ} \mathrm{C}$. The sampling was done and analyzed through TLC, CE and HPAEC-PAD. Various methods were used for the fractionation of oligosaccharides such as diafiltration, yeast treatment, activated charcoal adsorption. Many researchers used size exclusion chromatography for the separation of carbohydrates (Tzortzis et al. 2005). After reduction of monosaacharides, the synbiotic product containing $S$. boulardii and GOS was produced and lyophilized. The previous studies showed that $S$. boulardii was preserved after lyophilization and used as treatment for gastrointestinal disorders. But there is no study that shows the combination of $S$ boulardii and GOS in lyophilized form. This yeast is non-pathogenic and shows its beneficial effects through several modes of action i.e. competition with pathogens, inhibits pathogens from adhesion and neutralize the bacterial virulence factors and toxins (Sougioultzis et al., 2006).

The in vitro bifidogenic effect of sugars, GOS and synbiotic product was determined in present research work. Lactobacillus and Bifidobacterium were isolated from infant fecal sample on MRS agar through serial dilution method. After isolation, one colony of each bacterium was inoculated in MRS broth in two different set of test tubes containing glucose, lactose, GOS and GOS treated with $S$. boulardii. The incubation was occurred at $37^{\circ} \mathrm{C}$ anaerobically for $48 \mathrm{hr}$. Then, the growth of bacteria was checked spectophotometrically at $\mathrm{OD}_{600}$. In case of Lactobacillus the OD values were 0.567 for glucose, 0.490 for GOS and 0.508 for synbotic product. It shows that synbiotic product is more effective as compared to GOS. The OD values for Bifidobacterium were 0.402 for glucose, 0.433 for GOS and 0.432 for synbiotic product. It shows that the effect of GOS and synbiotic product are almost same.

\section{CONCLUSION}

The GOS was produced from $\beta$-galactosidase enzyme using lactose through transgalactosylation. The maximum production of GOS occurs after $5 \mathrm{hr}$ at $37^{\circ} \mathrm{C}$ with phosphate buffer ( $\mathrm{pH}$ 6.5). The probiotic $S$. boulardii was grown and used for the treatment of GOS mixture. After that synbiotic product was developed and subjected to lyophilized procedure. Then, total yeast count was determined. The in vitro bifidogenic effect was determined. Bifidobacterium shows more positive effect towards prebiotic and combined effect of prebiotic and probiotic as compared to Lactobacillus.

Acknowledgments: We thank Amber Javid and Waqas Saleem from PKLI \& $\mathrm{RC}$ for their assistance in preparing the manuscript and providing guidelines to this work. We are also thankful to the Department of Microbiology, University of Veterinary and Animal Sciences for providing all the facilities related to this research. The content is solely responsibility of the authors

\section{REFERENCES}

Geyik, M. F., Aldemir, M., Hosoglu, S., Ayaz, C., Satilmis, S., Buyukbayram, H , \& Kokoglu, O. F. (2006). The Effects ofSaccharomyces boulardiion Bacterial T ranslocation in Rats with Obstructive Jaundice. The Annals of The Royal College of Surgeons of England, 88(2), 176-180. http://dx.doi:10.1308/003588406x9498

Goulas, T. K., Goulas, A. K., Tzortzis, G., \& Gibson, G. R. (2007). Molecular clo ning and comparative analysis of four $\beta$-galactosidase genes from Bifidobacteriu $\mathrm{m}$ bifidum NCIMB41171. Applied Microbiology and Biotechnology, 76(6), 1365 -1372. http://dx.doi:10.1007/s00253-007-1099-1

Hernández, O., Ruiz-Matute, A. I., Olano, A., Moreno, F. J., \& Sanz, M. L. (2009 ). Comparison of fractionation techniques to obtain prebiotic galactooligosacchari des. International Dairy Journal, 19(9), 531-536. http://dx.doi:10.1016/j.idairyj. 2009.03.002

Kaplan, H., \& Hutkins, R. W. (2000). Fermentation of Fructooligosaccharides by Lactic Acid Bacteria and Bifidobacteria. Applied and Environmental Microbiolog y, 66(6), 2682-2684. http://dx.doi:10.1128/aem.66.6.2682-2684.2000

Kirsten, M., Kimaro, D. N., Feger, K.-H., \& Kalbitz, K. (2019). Impact of land us e on soil organic carbon stocks in the humid tropics of NE Tanzania. Journal of $P$ lant Nutrition and Soil Science, 182(4), 625-636. http://dx.doi:10.1002/jpln.2018 00595
Kunová, G., Rada, V., Lisová, I., Ročková, Š., \& Vlková, E. (2012). In vitro ferm entability of prebiotic oligosaccharides by lactobacilli. Czech Journal of Food Sci ences, 29(Special Issue), S49-S54. http://dx.doi:10.17221/306/2011-cjfs

Leroy, F., \& De Vuyst, L. (2004). Lactic acid bacteria as functional starter cultur es for the food fermentation industry. Trends in Food Science \& Technology, 15( 2), 67-78. http://dx.doi:10.1016/j.tifs.2003.09.004

Macfarlane, G. T., Steed, H., \& Macfarlane, S. (2007). Bacterial metabolism and health-related effects of galacto-oligosaccharides and other prebiotics. Journal of Applied Microbiology, 0(0), 070907095856003-??? http://dx.doi:10.1111/j.13652672.2007.03520.x

Osborn, D. A., \& Sinn, J. K. (2007). Prebiotics in infants for prevention of allergi $\mathrm{c}$ disease and food hypersensitivity. Cochrane Database of Systematic Reviews. $\mathrm{h}$ ttp://dx.doi:10.1002/14651858.cd006474.pub2

Qamar, A., Aboudola, S., Warny, M., Michetti, P., Pothoulakis, C., LaMont, J. T. , \& Kelly, C. P. (2001). Saccharomyces boulardii Stimulates Intestinal Immunogl obulin A Immune Response to Clostridium difficile Toxin A in Mice. Infection a nd Immunity, 69(4), 2762-2765. http://dx.doi:10.1128/iai.69.4.2762-2765.2001

Rodriguez-Colinas, B., Kolida, S., Baran, M., Ballesteros, A. O., Rastall, R. A., \& Plou, F. J. (2013). Analysis of fermentation selectivity of purified galacto-olig osaccharides by in vitro human faecal fermentation. Applied Microbiology and $\mathrm{Bi}$ otechnology, 97(13), 5743-5752. http://dx.doi:10.1007/s00253-013-4892-Z

Rossi, M., Corradini, C., Amaretti, A., Nicolini, M., Pompei, A., Zanoni, S., \& M atteuzzi, D. (2005). Fermentation of Fructooligosaccharides and Inulin by Bifido bacteria: a Comparative Study of Pure and Fecal Cultures. Applied and Environm ental Microbiology, 71(10), 6150-6158. http://dx.doi:10.1128/aem.71.10.6150-6 158.2005

Sanders, M. E., Merenstein, D. J., Reid, G., Gibson, G. R., \& Rastall, R. A. (2019 ). Probiotics and prebiotics in intestinal health and disease: from biology to the cli nic. Nature Reviews Gastroenterology \& Hepatology, 16(10), 605-616. http://dx. doi:10.1038/s41575-019-0173-3

Schaafsma, G. (2008). Lactose and lactose derivatives as bioactive ingredients in human nutrition. International Dairy Journal, 18(5), 458-465. http://dx.doi:10.10 16/j.idairyj.2007.11.013

Sharma, P., Kessler, W. J., Bogner, R., Thakur, M., \& Pikal, M. J. (2019). Applic ations of the Tunable Diode Laser Absorption Spectroscopy: In-Process Estimati on of Primary Drying Heterogeneity and Product Temperature During Lyophiliza tion. Journal of Pharmaceutical Sciences, 108(1), 416-430. http://dx.doi:10.1016 lj.xphs.2018.07.031

Sougioultzis, S., Simeonidis, S., Bhaskar, K. R., Chen, X., Anton, P. M., Keates, S., ... Kelly, C. P. (2006). Saccharomyces boulardii produces a soluble anti-infla mmatory factor that inhibits NF- $\mathrm{B}$-mediated IL-8 gene expression. Biochemical and Biophysical Research Communications, 343(1), 69-76. http://dx.doi:10.1016 /j.bbrc.2006.02.080

Splechtna, B., Nguyen, T.-H., \& Haltrich, D. (2007). Comparison between Disco ntinuous and Continuous Lactose Conversion Processes for the Production of Pre biotic Galacto-oligosaccharides Using $\beta$-Galactosidase fromLactobacillus reuteri. Journal of Agricultural and Food Chemistry, 55(16), 6772-6777. http://dx.doi:10 $.1021 / \mathrm{jf} 070643 \mathrm{z}$

Splechtna, B., Nguyen, T.-H., Zehetner, R., Lettner, H. P., Lorenz, W., \& Haltric h, D. (2007). Process development for the production of prebiotic galacto-oligosa ccharides from lactose using $\beta$-galactosidase fromLactobacillus sp. Biotechnolog y Journal, 2(4), 480-485. http://dx.doi:10.1002/biot.200600230

Tzortzis, G., Goulas, A. K., Gee, J. M., \& Gibson, G. R. (2005). A Novel Galacto oligosaccharide Mixture Increases the Bifidobacterial Population Numbers in a C ontinuous In Vitro Fermentation System and in the Proximal Colonic Contents of Pigs In Vivo. The Journal of Nutrition, 135(7), 1726-1731. http://dx.doi:10.1093/ jn/135.7.1726

Tzortzis, G., \& Vulevic, J. (2009). Galacto-Oligosaccharide Prebiotics. Prebiotic $s$ and Probiotics Science and Technology, 207-244. http://dx.doi:10.1007/978-0 387-79058-9_7

Underwood, M. A., Salzman, N. H., Bennett, S. H., Barman, M., Mills, D. A., M arcobal, A., ... Sherman, M. P. (2009). A Randomized Placebo-controlled Comp arison of 2 Prebiotic/Probiotic Combinations in Preterm Infants: Impact on Weig ht Gain, Intestinal Microbiota, and Fecal Short-chain Fatty Acids. Journal of Ped atric Gastroenterology and Nutrition, 48(2), 216-225. http://dx.doi:10.1097/mpg. Ob013e31818de195

Yazdi, M., Hafezi, P., \& Abbassi, R. (2019). A methodology for enhancing the reliability of expert system applications in probabilistic risk assessment. Journal of Loss Prevention in the Process Industries, 58, 51-59. http://dx.doi:10.1016/j.jlp.2019.02.001 